\title{
Comparison of tungsten films grown by CVD and hot-wire assisted atomic layer deposition in a cold-wall reactor
}

\author{
Mengdi Yang, a) Antonius A. I. Aarnink, Alexey Y. Kovalgin, Dirk. J. Gravesteijn, \\ Rob A. M. Wolters, and Jurriaan Schmitz \\ MESA+ Institute for Nanotechnology, University of Twente, P.O. Box 217, 7500 AE Enschede, \\ The Netherlands
}

(Received 28 August 2015; accepted 11 November 2015; published 25 November 2015)

\begin{abstract}
In this work, the authors developed hot-wire assisted atomic layer deposition (HWALD) to deposit tungsten (W) with a tungsten filament heated up to $1700-2000^{\circ} \mathrm{C}$. Atomic hydrogen (at-H) was generated by dissociation of molecular hydrogen $\left(\mathrm{H}_{2}\right)$, which reacted with $\mathrm{WF}_{6}$ at the substrate to deposit $\mathrm{W}$. The growth behavior was monitored in real time by an in situ spectroscopic ellipsometer. In this work, the authors compare samples with tungsten grown by either HWALD or chemical vapor deposition (CVD) in terms of growth kinetics and properties. For CVD, the samples were made in a mixture of $\mathrm{WF}_{6}$ and molecular or atomic hydrogen. Resistivity of the $\mathrm{WF}_{6}-\mathrm{H}_{2} \mathrm{CVD}$ layers was $20 \mu \Omega \cdot \mathrm{cm}$, whereas for the $\mathrm{WF}_{6}$-at-H-CVD layers, it was $28 \mu \Omega \cdot \mathrm{cm}$. Interestingly, the resistivity was as high as $100 \mu \Omega \cdot \mathrm{cm}$ for the HWALD films, although the tungsten films were $99 \%$ pure according to X-ray photoelectron spectroscopy. X-ray diffraction reveals that the HWALD W was crystallized as $\beta$-W, whereas both CVD films were in the $\alpha-\mathrm{W}$ phase. (C) 2015 American Vacuum Society. [http://dx.doi.org/10.1116/1.4936387]
\end{abstract}

\section{INTRODUCTION}

Metallic layers (films) play a crucial role in manufacturing of semiconductor devices such as microprocessors, DRAM memories, flash memories, and image sensors. Commonly applied metals include aluminum (Al), copper $(\mathrm{Cu})$, titanium $(\mathrm{Ti})$, and tungsten $(\mathrm{W})$. Pure-metallic films are often deposited by physical vapor deposition (PVD, i.e., sputtering or evaporation) or by chemical vapor deposition (CVD). ${ }^{1-3}$ Complex structures and shrinking dimensions of modern microelectronic devices pose stringent demands on film conformity, uniformity, and step coverage in high aspect ratio structures. In this light, CVD and PVD-based technologies have their limitations. ${ }^{1,4}$

Atomic layer deposition (ALD) therefore recently gains ground from PVD and CVD for industrial use. ${ }^{5}$ A selflimiting reaction mechanism, the main feature of ALD, leads to an accurate thickness control and high film uniformity on arbitrarily shaped and patterned surfaces. ${ }^{6}$ However, ALD of single-element films, such as metals or semiconductors, is difficult to achieve by using thermal ALD processes. ${ }^{6}$ As a solution, plasma-enhanced ALD (PEALD), also called radical-enhanced ALD (REALD), can be utilized. For example, with PEALD, Pt can be grown by $\mathrm{O}_{2}$ plasma, ${ }^{7} \mathrm{Ru}$ (Refs. 8 and 9) and $\mathrm{Co}$ by $\mathrm{NH}_{3}$ plasma, ${ }^{10}$ and $\mathrm{Al}$ (Ref. 11) and $\mathrm{Cu}$ by $\mathrm{H}_{2}$ plasma. ${ }^{12}$ However, plasma can cause damage to the wafer by generated ions and UV light, ${ }^{13}$ in particular, to MOS transistors. In addition, a diversity of radicals is typically created in even simple one- or two-gas plasmas, enabling numerous chemical reactions besides the pursued one. Not all the reactions lead to the formation of high-quality films; certain plasma compounds can deteriorate film quality. This makes the composition and structure of the growing film hard to predict and control.

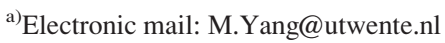

In this work, we propose an alternative method to generate radicals for REALD by means of a hot-wire (hot filament) instead of a plasma. It is well established that radicals can form upon dissociation of gas molecules on a hot tungsten (W) filament. ${ }^{14-18}$ For instance, molecular hydrogen $\left(\mathrm{H}_{2}\right)^{19-21}$ and $\mathrm{NH}_{3}$ (Ref. 22) can effectively decompose on a W filament heated up to $1500-2000^{\circ} \mathrm{C}$. By replacing plasma by a hot-wire, we aim to avoid substrate damage, limit the number of radicals formed, and thereby achieve a better control of the reactant supply to the growing surface.

Tungsten (W) is widely used for filling contacts and vias in microelectronic devices due to its inertness to many chemicals, compatibility with silicon technology, and the low enough electrical resistivity for contacts and vias. ${ }^{23} \mathrm{CVD}$ of $\mathrm{W}$ by $\mathrm{WF}_{6}$ gas and molecular $\mathrm{H}_{2}$ had been successfully established and applied in industry. An ALD procedure for W films, with all its advantages, will open new application areas for this metal. In this work, we compare three deposition methods of W: (1) CVD by using $\mathrm{WF}_{6}$ and molecular hydrogen $\left(\mathrm{H}_{2}-\mathrm{CVD}\right)$, (2) $\mathrm{CVD}$ by $\mathrm{WF}_{6}$ and atomic hydrogen (at-H-CVD), and (3) hot-wire assisted atomic layer deposition (HWALD) by sequential pulses of $\mathrm{WF}_{6}$ and atomic hydrogen. In our reactor, the hot-wire itself is not a source of tungsten; it provides only atomic hydrogen. Film properties, such as resistivity, roughness, density, and crystal structure, have been evaluated by means of four-point probe, atomic force microscope (AFM), $x$-ray diffraction (XRD) and reflection (XRR), and transmission electron microscopy (TEM).

\section{EXPERIMENT}

Tungsten (W) films were deposited on top of $100 \mathrm{~nm}$ silicon dioxide $\left(\mathrm{SiO}_{2}\right)$ thermally grown on $\mathrm{Si}(100)$ wafers. Before deposition of $\mathrm{W}$, the wafers were cleaned in fuming (99\%) $\mathrm{HNO}_{3}$ and boiling $69 \% \mathrm{HNO}_{3}$ to remove organic and 
metallic contaminations. Then, the substrate was dipped in $0.3 \% \mathrm{HF}$ solution for $3 \mathrm{~min}$. The procedure was reported to provide a surface on which $\mathrm{Si}$ could grow with high nucleation density. ${ }^{24}$

Tungsten nucleates very slowly on $\mathrm{SiO}_{2}{ }^{25}$ To circumvent this problem, a 4-nm thin $\mathrm{W}$ seed layer was preformed on $\mathrm{SiO}_{2}$ before starting the actual CVD or ALD of W. The formation of this seed layer consisted of (1) CVD of a thin $(5 \mathrm{~nm})$ layer of amorphous $\mathrm{Si}(\mathrm{a}-\mathrm{Si})$ from trisilane $\left(\mathrm{Si}_{3} \mathrm{H}_{8}\right)$ at $325^{\circ} \mathrm{C}$; and (2) converting the a-Si into $\mathrm{W}$ by reacting with $\mathrm{WF}_{6}$. The final thickness of the $\mathrm{W}$ seed layer, as measured by spectroscopic ellipsometer (SE), was around $3 \mathrm{~nm}$. More details about the formation of this seed layer can be found elsewhere. ${ }^{26}$ Upon this seed layer, W films were further deposited by one of the three methods, without vacuum break. Finally, an approximately $5 \mathrm{~nm}$ thick a-Si was deposited on top of $\mathrm{W}$ as a capping layer, to prevent oxidation of the $\mathrm{W}$ layer. As demonstrated in the earlier publications of the group, such a capping layer can effectively protect a metallic surface for a long time against native oxidation. ${ }^{27}$

\section{A. Delivery of at-H to the substrate}

The cold-wall reactor used to deposit tungsten films is schematically shown in Fig. 1. The reactor was equipped with an in situ Woollam M-2000 SE operating in the wavelength range between 245 and $1688 \mathrm{~nm}$, combined with COMPLETEEASE software. The SE enabled in situ monitoring of the deposition process in real time.

The hot-wire source of at-H (a tungsten filament) is installed on top of the reaction chamber (see Fig. 1). Molecular hydrogen is introduced via this source at a distance of approximately $70 \mathrm{~cm}$ above the substrate. There is no direct line of sight between the hot-wire and the substrate. ${ }^{28,29} \mathrm{WF}_{6}$ is supplied through the gas ring, situated around $10 \mathrm{~cm}$ above the substrate.

To verify the existence of at- $\mathrm{H}$ and its efficient delivery over $70 \mathrm{~cm}$ from the source to the substrate, tellurium (Te) etching experiments were carried out before starting the work on W film deposition. Te reacts with at- $\mathrm{H}$ at room temperature to form volatile tellurium hydride $\left(\mathrm{TeH}_{2}\right){ }^{30}$ however, the reaction between Te and molecular hydrogen $\left(\mathrm{H}_{2}\right)$

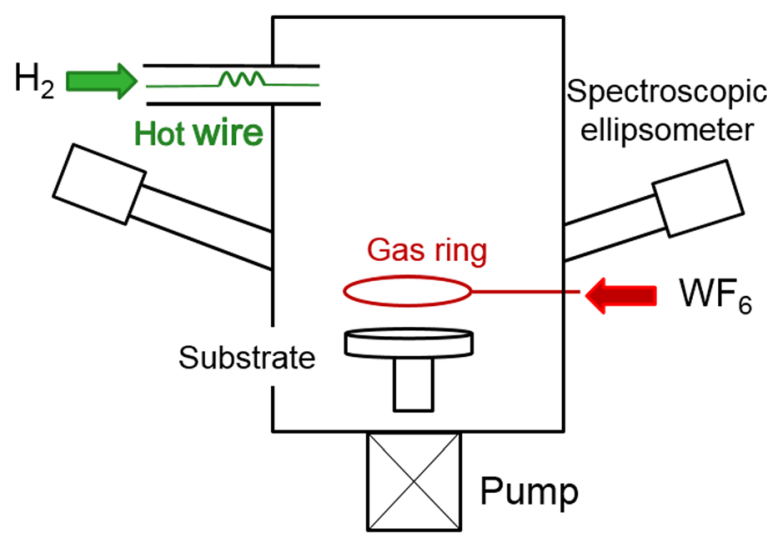

FIG. 1. (Color online) Schematic cross-section of the cold-wall reactor used in this work. does not occur. Therefore, the observation of etching of a Te film in hydrogen ambient at room temperature can confirm the existence of at- $\mathrm{H}^{23}$

Our previous work, using the same hot-wire source, has demonstrated the high etching rate of $\mathrm{Te}$ by at- $\mathrm{H}$, greatly depending on the hot-wire temperature. ${ }^{28}$ To enable HWALD, well-defined pulses of at-H must be provided instead of a continuous flow. We therefore confirmed the ability to reliably supply at-H for HWALD in the following experiments (see Fig. 2). First, the Te film could not be etched with the hot-wire off while exposed to $\mathrm{H}_{2}$ flow (as expected). Second, with hot-wire on while exposed to argon or nitrogen, the Te film could not be etched either. The three regimes indicated in Fig. 2 manifest that only the combination of a switched-on hot-wire with $\mathrm{H}_{2}$ flow through the hot-wire source effectively etches the Te film. The latter is demonstrated in Fig. 2, where Te etching occurs by each pulse of at- $\mathrm{H}$ of $0.1 \mathrm{~s}$; the etching quickly diminishes and stops during a purge of $30 \mathrm{~s}$ with Ar. As the figure further indicates, there is no delay between the injection of $\mathrm{H}_{2}$ and the on-set of etching; however, etching tends to continue for another $8 \mathrm{~s}$ after the $0.1 \mathrm{~s}$ pulse of hydrogen. This is attributed to the residence time of at-H in the reaction chamber. In conclusion, etching of Te films confirms not only the efficient delivery of at-H to the substrate but also its sufficiently long lifetime in the reactor.

It is important to estimate the dissociation degree of molecular hydrogen by the hot wire. We thoroughly addressed this issue in our earlier publication. ${ }^{28}$ The accurate estimation requires chemical modeling of the etching reactions including knowing the sticking probability of at-H to the surface, reaction rate constants, and also taking the decomposition of the formed $\mathrm{TeH}_{2}$ (i.e., redeposition) into account. Unfortunately, several unknown parameters of this process make it rather difficult to estimate the amount of at- $\mathrm{H}$

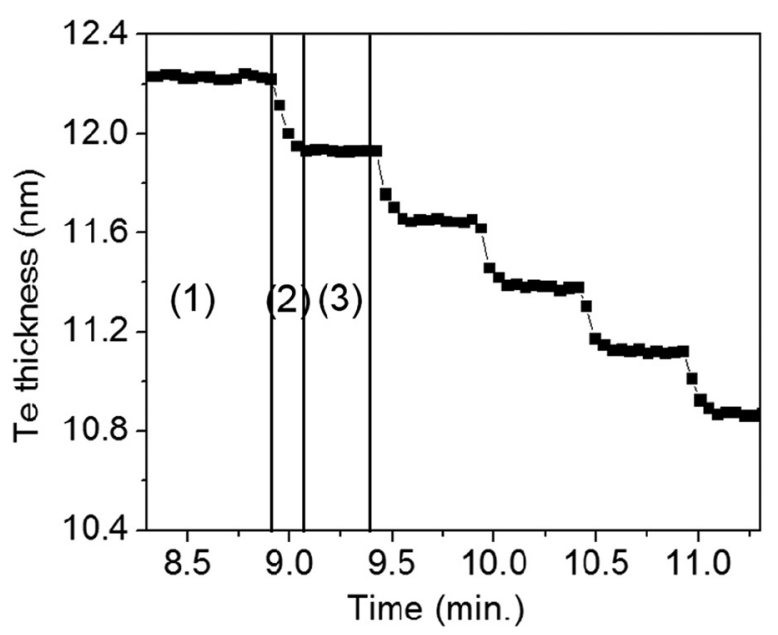

FIg. 2. Etching a Te film by sequential $0.1 \mathrm{~s}$ pulses of at-H followed by $30 \mathrm{~s}$ purge. The thickness of the remaining Te on a silicon wafer as measured by SE is shown. Conditions: room substrate temperature, process pressure of 0.003 mbar, $\mathrm{H}_{2}$ flow rate of $100 \mathrm{sccm}$, and a carrier gas (Ar) flow rate of 50 sccm. Three regimes are identified: (1) introducing molecular hydrogen $\left(\mathrm{H}_{2}\right)$, hot-wire off; (2) introducing $\mathrm{H}_{2}$ via the hot-wire kept at $1750{ }^{\circ} \mathrm{C}$; and (3) Ar flowing through the hot-wire at $1750^{\circ} \mathrm{C}$. 
produced. However, in Ref. 28, we estimated the minimum amount of at-H needed to maintain the experimental etching rates. The following assumptions were made: (1) all generated at-H could reach the surface to etch $\mathrm{Te}$, and (2) no redeposition of Te occurs. Under these assumptions, it was calculated that the dissociation degree of $\mathrm{H}_{2}$ into at- $\mathrm{H}$ should be at least $8 \%$. The actually generated amount of at- $\mathrm{H}$ should be higher but at least such amount is needed (assuming $100 \%$ participation in the reactions, sticking probability 1 , etc.) to maintain the experimental etch rates.

\section{B. Film deposition}

As mentioned, the samples were deposited either by $\mathrm{H}_{2}-$ CVD, at-H-CVD, or HWALD. One HWALD cycle consisted of a 10-s pulse of at- $\mathrm{H}\left(\mathrm{H}_{2}\right.$ flow of $100 \mathrm{sccm}$ through the source) followed by an Ar purge of $20 \mathrm{~s}$, then a 0.1-s pulse of $\mathrm{WF}_{6}(2 \mathrm{sccm})$, and finally another Ar purge of $30 \mathrm{~s}$. Importantly, the hot-wire itself was not acting as a source of tungsten, as no deposition of $\mathrm{W}$ occurred during the purge pulses with hot-wire on. This confirms no transport of $\mathrm{W}$ from the hot-wire to the surface via the gas phase. The HWALD was conducted at 0.15 mbar and a substrate temperature of $315^{\circ} \mathrm{C}$. Additional details may be found in our previous work. ${ }^{26}$ For the CVD modes, $\mathrm{WF}_{6}$ and either $\mathrm{H}_{2}$ or at- $\mathrm{H}$ were mixed in the gas phase to form either $\mathrm{H}_{2}-\mathrm{CVD}$ or at-H-CVD tungsten films.

The process conditions are detailed in Table I. To find the ALD window with self-limiting surface reactions, all the deposition parameters were carefully adjusted in our earlier work, as described in Ref. 26. Due to the coexistence of ALD, CVD, and etching processes, as mentioned in the reference, the choice of conditions was limited. For HWALD, the conditions (pressure, pulse times, etc.) were optimized such that this mode was the dominant. To enhance the CVD modes, while suppressing the negative effect of etching, the conditions should be adapted accordingly. Importantly, $\mathrm{H}_{2}$ CVD W was deposited at $325^{\circ} \mathrm{C}$ as a very low deposition was observed at $315^{\circ} \mathrm{C}$ and 0.15 mbar. It was found that, at a pressure higher than 0.15 mbar, etching of the deposited tungsten by fluorine dominated rather than CVD, presumably due to the dissociation of $\mathrm{WF}_{6}$ upon the hot-wire, resulting in the enhanced formation of fluorine. ${ }^{26}$ Concerning the at-H-CVD, it only took place at a pressure much lower than $0.15 \mathrm{mbar}$. Therefore, a pressure of $0.003 \mathrm{mbar}$ was chosen.

\section{Film characterization}

A PANalytical X'PERT MPD diffractometer was utilized for XRD and XRR measurements. XRD and XRR patterns of the samples were recorded in the region of $2 \theta=30^{\circ}-90^{\circ}$ using $\mathrm{Cu} \mathrm{K} \alpha$ radiation, with a PANalytical PIXcel1D detector.

The film thickness was measured in real-time during the deposition using the in situ spectroscopic ellipsometer described in Sec. II A. The measurements were taken every $2.5 \mathrm{~s}$. Due to the opacity of $\mathrm{W}$, only the films with thickness up to $30 \mathrm{~nm}$ could be measured by SE. The film thickness was verified by high-resolution scanning electron microscopy (HR-SEM) and XRR. Additionally, optical properties of the films were also obtained by SE.

Figure 3 shows cross-sectional HR-SEM images of a HWALD tungsten sample with a capping layer of approximately $5 \mathrm{~nm}$. Thicknesses of the $\mathrm{W}$ seed layer and HWALD W layer, determined by SE, are roughly 3 and $13 \mathrm{~nm}$, respectively. Figure 3(a) presents the normal InLens image where the a-Si capping layer cannot be distinguished; the total thickness of all sublayers (approx. $20 \mathrm{~nm}$ by SE) is in agreement with the value of $17 \mathrm{~nm}$ obtained by HR-SEM. The energy selective backscattered (ESB) image in Fig. 3(b) exhibits a better contrast between the a-Si and the $\mathrm{W}$ layer underneath, giving a total thickness of the two tungsten layers (bright-gray) of approx. 12 nm. Furthermore, Fig. 3(a) indicates a remarkable surface roughness (see further Sec. III B). Considering the roughness of a few nanometers and different measurement positions on the wafer for SE and HR-SEM, the thickness determined by $\mathrm{SE}$ is in good agreement with that measured by HR-SEM.

Table II compares thicknesses of samples deposited by three different methods. The thicknesses measured by XRR are smaller than those obtained by SE. To note, the SE measured in the center of the wafer, sometimes without having a$\mathrm{Si}$ capping layer on $\mathrm{W}$, whereas the XRR measurements were always done on the wafer with the capping layer and on an area adjacent to the center of the wafer. Both differences may have caused the small discrepancy in thickness. We conclude from Table II and Fig. 3 that thicknesses measured by SE, HR-SEM, and XRR are in good agreement. This confirms the validity of SE for measuring W films within their transparency range, i.e., up to $30 \mathrm{~nm}$.

The film resistivity was examined by an automatic fourpoint probe stage of Polytec. The film surface morphology was characterized by a Bruker Fastscan/ICON model AFM. Further, TEM and energy filtered TEM (EFTEM) were utilized to characterize grown films.

\section{RESULTS AND DISCUSSION}

\section{A. Resistivity and density}

The resistivity results are shown in Table III. To avoid misunderstanding, it should be emphasized that we have

TABLE I. Deposition conditions for samples made by three different methods. The film thickness was measured by in situ SE.

\begin{tabular}{lccccc}
\hline \hline Deposition method & Process Pressure (mbar) & Substrate temperature $\left({ }^{\circ} \mathrm{C}\right)$ & Hot-wire temperature $\left({ }^{\circ} \mathrm{C}\right)$ & Gas flow rate $\mathrm{H}_{2} / \mathrm{WF}_{6}\left(\mathrm{sccm}^{2}\right)$ & $\mathrm{Growth} \mathrm{rate}^{\mathrm{a}}$ \\
\hline $\mathrm{H}_{2}$-CVD W & 0.15 & 325 & 25 & $100 / 2$ & $1.430 \mathrm{~nm} / \mathrm{min}$ \\
At-H-CVD W & 0.003 & 315 & 1750 & $100 / 2$ & $0.104 \mathrm{~nm} / \mathrm{min}$ \\
HWALD W & 0.15 & 315 & 1750 & $100 / 2$ & $0.006 \mathrm{~nm} / \mathrm{cycle}$ \\
\hline \hline
\end{tabular}

${ }^{\mathrm{a}}$ Growth rate was measured by SE at the center of the wafer. 

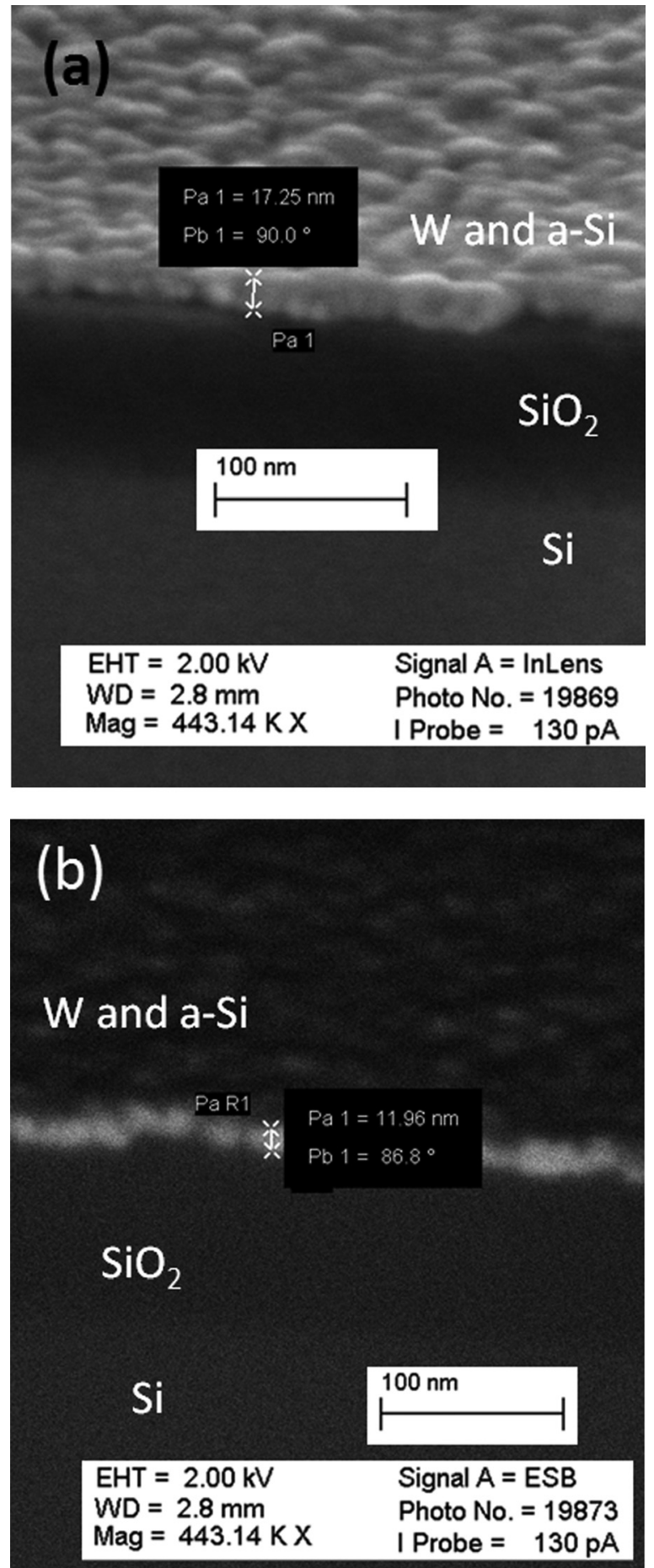

FIG. 3. Cross-sectional HR-SEM images of a HWALD tungsten film. The tungsten layer is covered by an approximately $5 \mathrm{~nm}$ thick a-Si layer. (a) The standard Inlens detection, showing the total thickness of all tungsten and a-Si sublayers of approximately $17 \mathrm{~nm}$. (b) The result of energy selective backscattered detection, where approximately $12 \mathrm{~nm}$ thick W layers (bright-gray) can be visualized. $\mathrm{P}_{\mathrm{a}}$ is the measured thickness (i.e., length of the $\uparrow$-line), and $\mathrm{P}_{\mathrm{b}}$ is the angle between the $\uparrow$-line and the substrate surface.

carried out many experiments and many films thinner than $10 \mathrm{~nm}$ were grown. The stable spectroscopic ellipsometer model indicated comparable film properties including resistivity for all samples, which meant that films were deposited in a repeatable process. Finally, to demonstrate the
TABLE II. Comparison of thicknesses measured by SE and XRR at the center of the wafer.

\begin{tabular}{lcc}
\hline \hline Sample & Thickness by in situ SE (nm) & Thickness by XRR (nm) \\
\hline $\mathrm{H}_{2}$-CVD W & 10.2 & 9.7 \\
At-H-CVD W & 24.6 & 20.2 \\
HWALD W & 13.9 & 11.2 \\
\hline \hline
\end{tabular}

comparisons, only three typical and representative films were selected. The resistivity we measured was comparable with that reported for bulk CVD-W films. Moreover, the thinnest $\mathrm{H}_{2}$-CVD film $(10 \mathrm{~nm})$ showed the lowest resistivity, and a comparable resistivity was obtained for a 20-nm at-HCVD film. In contrast, a 13-nm HWALD W film showed a resistivity nearly five times as high as that of the CVD samples. These results revealed that thickness was not the key factor to determine resistivity in our experiment.

The lowest resistivity was obtained with $\mathrm{H}_{2}-\mathrm{CVD} \mathrm{W}$; however, the reader is reminded that this W layer was deposited at a slightly higher substrate temperature (Table I). In the literature, the lowest resistivity obtained by CVD with $\mathrm{WF}_{6}$ and $\mathrm{H}_{2}$ varies between 8 and $18 \mu \Omega \cdot \mathrm{cm} .{ }^{23}$ However, in these reports, the deposition temperature was above $400{ }^{\circ} \mathrm{C}$. The resistivity of at-H-CVD W was slightly higher but still comparable, taking the slightly lower growth temperature into account (Tables III and I).

The density of the tungsten films was obtained by XRR measurements. As $\mathrm{W}$ deposition and the seed layer formation were two different processes, the densities and thicknesses of these two layers were fitted separately. The obtained density of $\mathrm{W}$ seed layer was around $17.3 \mathrm{~g} / \mathrm{cm}^{3}$. The density of bulk tungsten ranges from 15.8 to $19.25 \mathrm{~g} /$ $\mathrm{cm}^{3}$, depending on its crystal phase, ${ }^{23,31}$ while most industrially manufactured $\alpha$-phase $\mathrm{W}$ exhibits the highest density of $19.25 \mathrm{~g} / \mathrm{cm}^{3}$. W films realized by at-H-CVD possessed the highest density, close to that of $\alpha-\mathrm{W}$ (Table III). The density of $\mathrm{H}_{2}-\mathrm{CVD} \mathrm{W}$ was $2.3 \%$ lower. HWALD W exhibited the lowest density and the highest resistivity. The possible reasons for this will be discussed in Sec. III D.

\section{B. Surface roughness}

Roughness of the seed and capping layers contributes to the resulting film roughness. It is known that a thicker a-Si seed layer will lead to a rougher surface of $\mathrm{W}$ after the reaction between $\mathrm{WF}_{6}$ and a-Si. ${ }^{32}$ In order to estimate the roughness of the surface before the depositions under study, a

TABLE III. Density (from XRR) and resistivity (by four-point probe) values of W films deposited by three different methods.

\begin{tabular}{lcc}
\hline \hline Sample & Density $^{\mathrm{a}}\left(\mathrm{g} / \mathrm{cm}^{3}\right)$ & Resistivity $^{\mathrm{a}}(\mu \Omega \cdot \mathrm{cm})$ \\
\hline $\mathrm{H}_{2}$ CVD W & 18.75 & 20 \\
At-H-CVD W & 19.19 & 28 \\
HWALD W & 17.15 & 100 \\
\hline \hline
\end{tabular}

${ }^{\mathrm{a}}$ All measurements were taken at the center of the wafer. 
$\mathrm{SiO}_{2}$ substrate, a 5-nm a-Si layer, and a $\mathrm{W}$ seed layer obtained after converting the a-Si into the $\mathrm{W}$ were measured by AFM (Fig. 4). Further, the roughness evolution during the subsequent deposition of $\mathrm{W}$ films was measured by AFM (Fig. 5). As the measurements have been done in air, one should realize that such thin layers will (partially) oxidize; although this may slightly affect the roughness, still comparisons between different depositions are possible.

Figure 4 shows a smooth surface of a HF-treated $\mathrm{SiO}_{2}$ substrate $(\mathrm{RMS}=0.25 \mathrm{~nm}), \mathrm{a}-\mathrm{Si}$ layer $(\mathrm{RMS}=0.018 \mathrm{~nm})$ and a rougher $\mathrm{W}$ seed layer $(\mathrm{RMS}=1.67 \mathrm{~nm})$. In Fig. 5, the AFM images of the three $\mathrm{W}$ depositions are presented. It can be seen that at-H-CVD provided the smoothest film. The $\mathrm{H}_{2}$ CVD film exhibits a rougher surface, probably due to the higher substrate temperature. The roughness profiles of $\mathrm{H}_{2}$ CVD W and HWALD W both exhibit sharp height variations with peak-valley difference reaching $20 \mathrm{~nm}$. In contrast, the profile of at-H-CVD W shows a much smaller difference. As the at-H-CVD film is approximately twice as thick as the other two films, its relative roughness is even lower. While further analyzing Fig. 5, it can be concluded that $\mathrm{H}_{2}-\mathrm{CVD} \mathrm{W}$ exhibits the smallest correlation length and at-H-CVD W has the biggest. This can be related to (1) a difference in the nucleation site density and (2) either vertically or laterally dominant growth. Atomic hydrogen obviously plays a crucial role in the growth mechanism, smoothing the film surface for at-H-CVD. The big thickness peak-to-valley variations which are comparable with the film thickness are
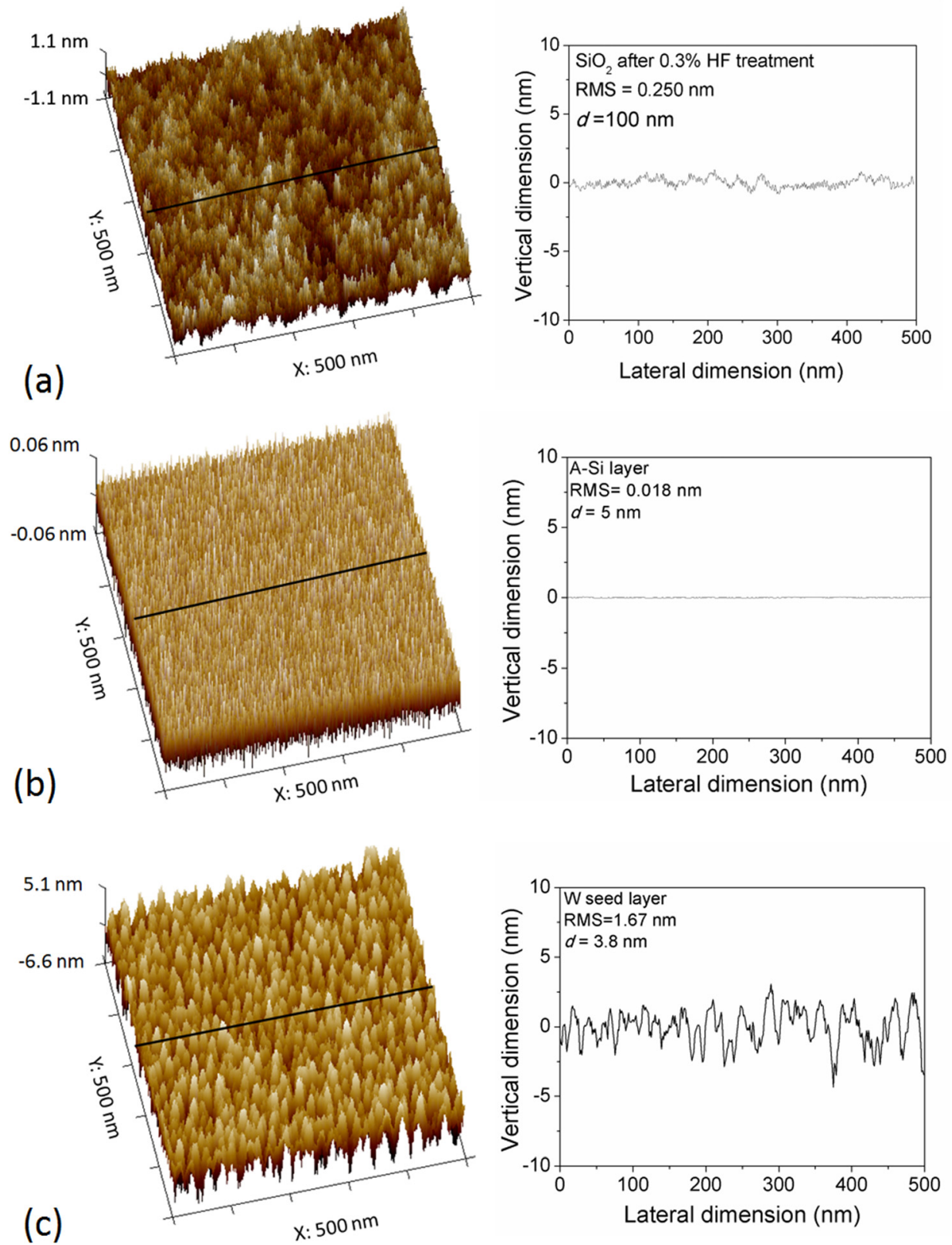

FIG. 4. (Color online) Surface morphology of (a) $\mathrm{SiO}_{2}$ substrate dipped in $0.3 \% \mathrm{HF}$, (b) 5 -nm a-Si layer, and (c) W seed layer formed by reaction between the a-Si and $\mathrm{WF}_{6}$. Roughness (RMS) was measured by AFM and is shown on the right-side graphs; the thickness $d$ was obtained by SE. The graphs illustrate the height variation along the black lines drawn on the left-side AFM images. 

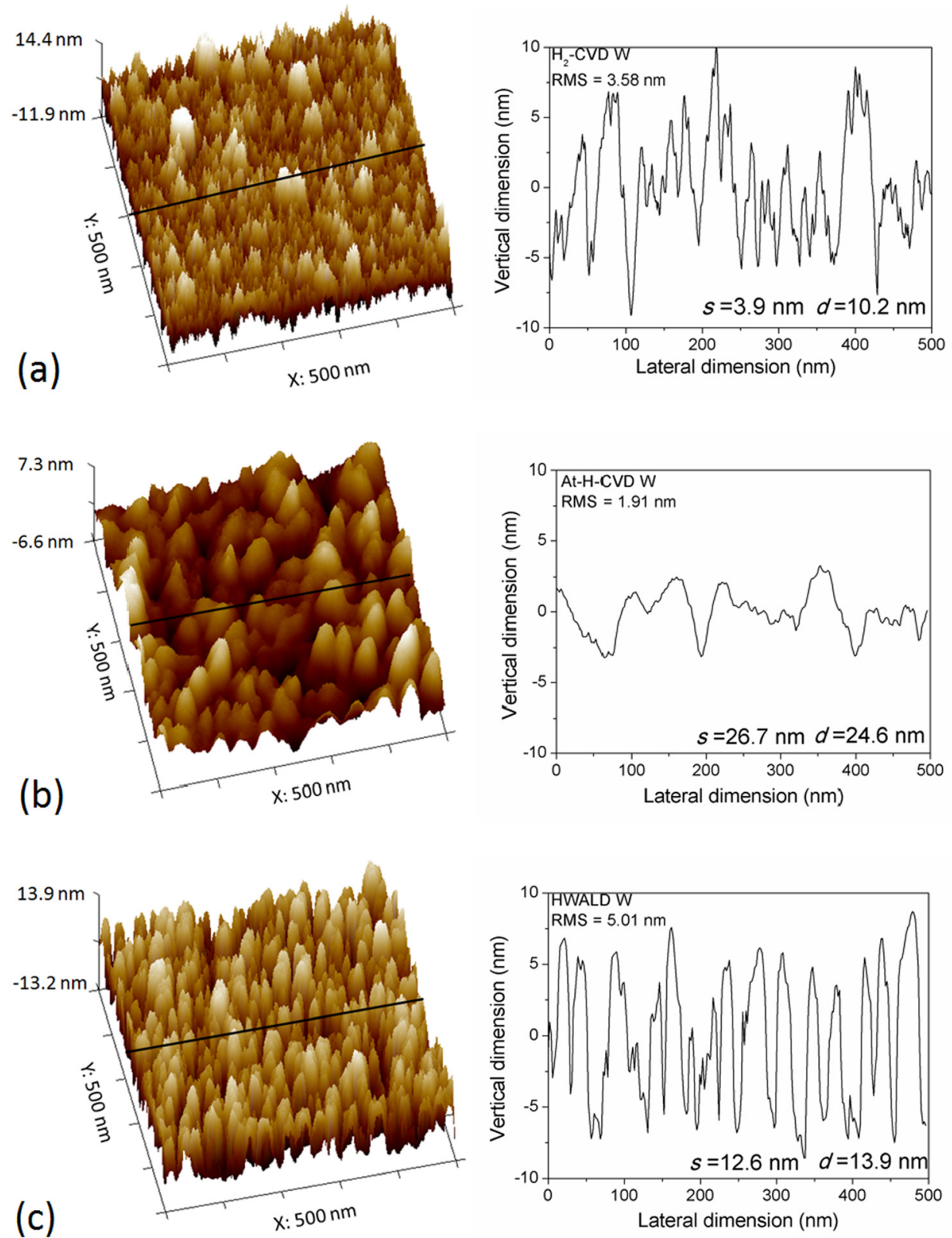

FIG. 5. (Color online) Surface morphology of (a) $\mathrm{H}_{2}$-CVD W deposited at $325^{\circ} \mathrm{C}$, (b) at-H-CVD W deposited at $315^{\circ} \mathrm{C}$, and (c) HWALD W deposited at $315^{\circ} \mathrm{C}$ (see Table I for other conditions). The roughness (RMS) was measured by AFM and is shown on the right-side graphs; the thickness $d$ was obtained by SE; the correlation length $s$ was extracted by the NANOSCOPE ANALYSIS software. The graphs illustrate the height variation along the black lines drawn on the left-side AFM images.

noticeable, especially in Figs. 5(a) and 5(c). However, the latter has a resistivity, which is five times that of the former. Thus, the difference in resistivity is not due to the high thickness variations. Nevertheless, this high variation will result in the lower mass density measured, especially for HWALD films. But only a relatively small difference in density is observed in our case.

\section{Film composition}

The compositional depth profile of the HWALD W film, measured by x-ray photoelectron spectroscopy (XPS), is presented in Fig. 6. No peak of fluorine (F) was found in the spectrum, indicating a good removal of $\mathrm{F}$ by at- $\mathrm{H}$. In the depth profile, three layers consisting of a-Si capping layer, deposited $\mathrm{W}$, and $\mathrm{SiO}_{2}$ underneath can be identified. The capping layer was oxidized on the top surface, but the oxygen concentration declined quickly while going deeper into the layer. The concentration of W in the HWALD W layer reached 99 at. \% with an oxygen signal below the detection limit.

In Fig. 7(a), a depth profile of the O1s-peak signal is demonstrated. Oxygen was observed at the surface and rapidly disappeared in the capping layer, consistent with the results of Fig. 6. It is noticeable that the O1s peak, present at the $\mathrm{W}-\mathrm{SiO}_{2}$ interface, corresponds to both $\mathrm{Si}-\mathrm{O}$ and $\mathrm{W}-\mathrm{O}$ bonding. In other words, at the $\mathrm{W}-\mathrm{SiO}_{2}$ interface, an O-to-W bond signal is clearly present. Likewise, the W4f peak of 


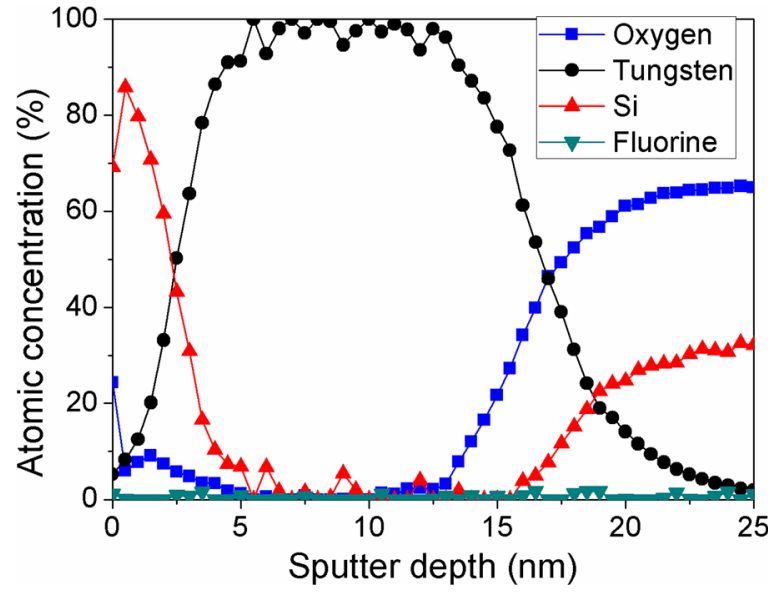

FIG. 6. (Color online) Compositional depth profile of a HWALD W film obtained by x-ray photoelectron spectroscopy.

tungsten with a binding energy of $32.1 \mathrm{eV}$, corresponding to bond of W-to-O of $\mathrm{SiO}_{2}$, can be noticed [Fig. 7(b)]. This implies the reaction between $\mathrm{W}$ of the film and $\mathrm{O}$ of $\mathrm{SiO}_{2}$ at the interface.
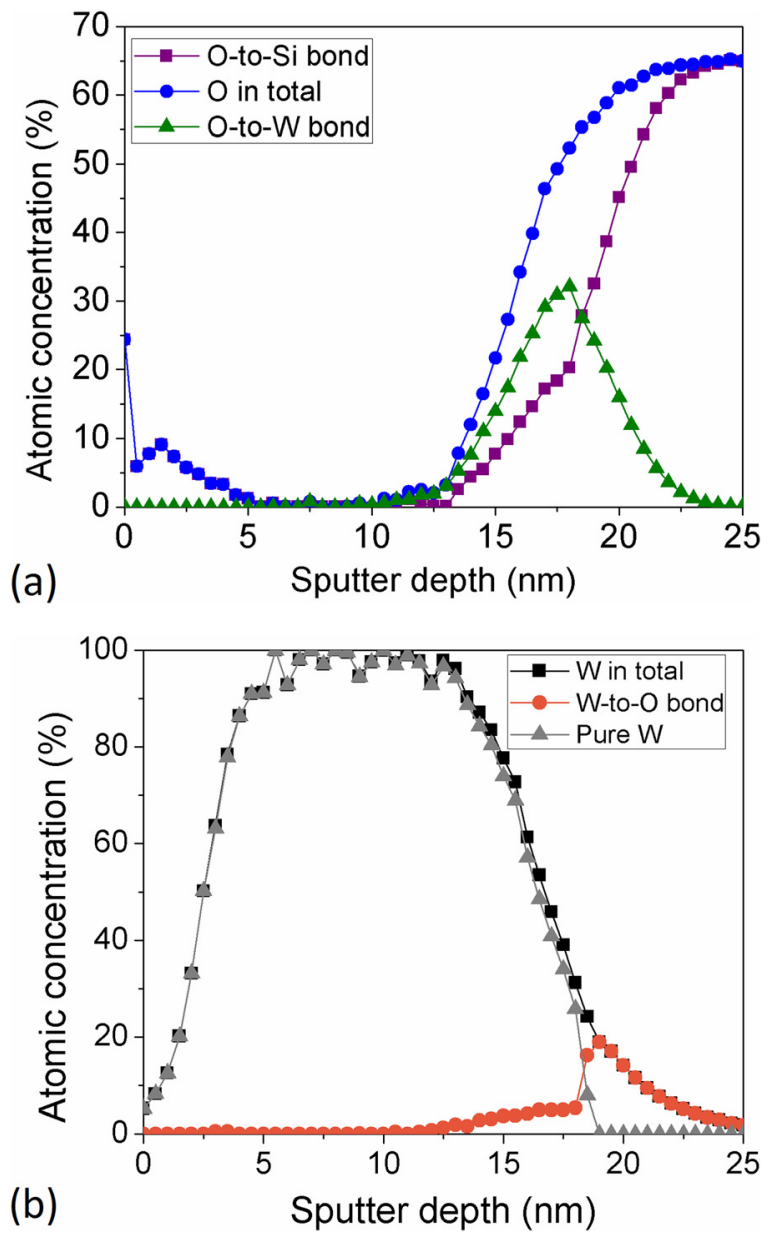

FIG. 7. (Color online) (a) Depth profile of the O1s signal. An oxygen signal is present in the top capping layer and the $\mathrm{SiO}_{2}$ substrate. A clear signal of O-to-W bond was observed at the $\mathrm{W}-\mathrm{SiO}_{2}$ interface. (b) The depth profile of the W4f signal. At the $\mathrm{W}-\mathrm{SiO}_{2}$ interface, some tungsten oxidation occurred.

\section{Crystallinity}

Apart from the amorphous phase, tungsten is known to exist in $\alpha, \beta$, and $\gamma$ crystal phases. ${ }^{31,33} \alpha-\mathrm{W}$ is the most stable phase; it has a body centered cubic lattice with a lattice constant of $0.316 \mathrm{~nm}^{34}$ The $\beta$-phase exhibits a cubic $\mathrm{A}_{3} \mathrm{~B}$ (A 15) crystal structure and is formed by $\mathrm{W}_{3} \mathrm{~W}$ or $\mathrm{W}_{3} \mathrm{O}$ clusters 35,36 with a lattice constant between 0.503 and $0.504 \mathrm{~nm}^{37}$ It is reported that the $\beta$-phase is metastable and can be transformed into the $\alpha$-phase upon annealing at $650-750{ }^{\circ} \mathrm{C} .^{38,39}$ In addition, the $\gamma$-phase has only been found at the beginning of sputtering and readily forms $\alpha-\mathrm{W} .^{23}$ For applications in semiconductor devices, $\alpha-\mathrm{W}$ is more desired attributed to its low resistivity; while $\beta$-W is adopted in transition edge sensors due to its superconducting properties where transition temperatures is as high as $4 \mathrm{~K}^{37,40}$

Figure 8 demonstrates the XRD patterns of $\mathrm{W}$ films deposited by the three mentioned methods. The strongest peak at $69^{\circ}$ corresponds to the (100) Si substrate. Because of the high intensity of this $\mathrm{Si}$ peak, three peaks of the $\beta$ phase in the range of $60^{\circ}-70^{\circ}$ are not visible. The distinguishable peaks of tungsten are located at $40.2^{\circ}$ [(110) plane], 58.2 [(200) plane], $73.2^{\circ}$ [(211) plane] and $87.1^{\circ}$ [(220) plane] for $\alpha-\mathrm{W},{ }^{33}$ and at $35.5^{\circ}$ [(002) plane], $39.8^{\circ}$ [(012) plane], $43.8^{\circ}$ [(112) plane], $86.2^{\circ}$ [(024) plane], and $88.7^{\circ}$ [(124) plane] for $\beta-\mathrm{W} .^{23,41}$ It is apparent from the graph that the unique peaks of $\beta-\mathrm{W}$ are only present in HWALD $\mathrm{W}$, whereas four peaks of $\alpha-\mathrm{W}$ can be observed in both CVD-films. Based on this measurement, it can be concluded that the HWALD W forms the $\beta$ phase in contrast to $\alpha-W$ obtained by both CVD methods.

The lattice constants of the three films in Fig. 8 have been calculated from the diffraction peak positions, revealing $0.505 \pm 0.001 \mathrm{~nm}$ for HWALD W, $0.315 \pm 0.001 \mathrm{~nm}$ for at$\mathrm{H}-\mathrm{CVD}$, and $0.316 \pm 0.001 \mathrm{~nm}$ for $\mathrm{H}_{2}-\mathrm{CVD}$. These values are consistent with the lattice constants reported for $\alpha$ and $\beta$ phases in the literature. In addition, the density of bulk $\alpha-\mathrm{W}$ is reported to be higher, ${ }^{23,31}$ with a typical value of $19.31 \mathrm{~g} /$ $\mathrm{cm}^{3}$, whereas that of the $\beta$-phase is $19.1 \mathrm{~g} / \mathrm{cm}^{3} . \beta$-W is also known to possess a high resistivity, above 100 and up to

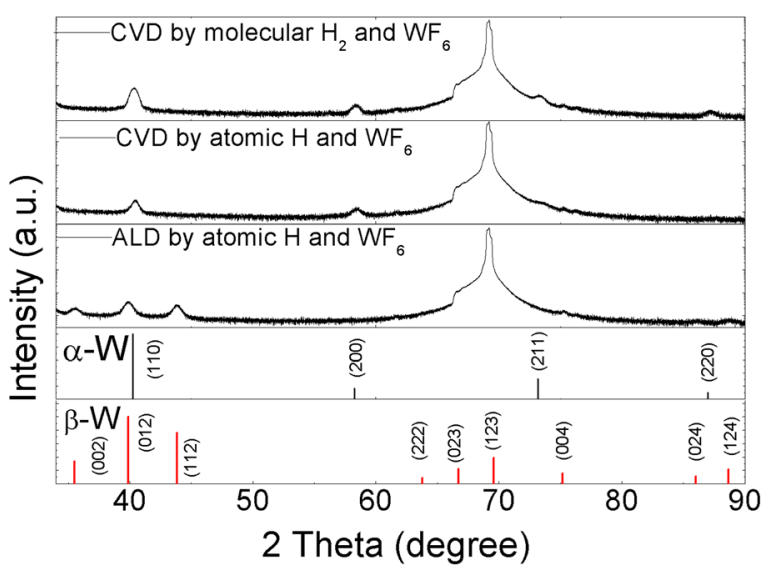

FIG. 8. (Color online) XRD patterns of W films deposited by three different methods. The diffraction peak positions and the corresponding attribution to $\alpha$ - and $\beta$-phases are shown (Refs. 23, 33, and 41). 
$1290 \mu \Omega \cdot \mathrm{cm},{ }^{36,42-44}$ compared to $5.6 \mu \Omega \cdot \mathrm{cm}$ for $\alpha-\mathrm{W}$. The lower density and higher resistivity of our HWALD film are in good agreement with the properties of $\beta$-W. Remarkably, our HWALD $\beta$-W films resemble the best examples of $\beta$-W grown up to date.

Further, based on the XRD peak patterns and Scherrer's equation, ${ }^{45}$ we evaluated the grain sizes. To note, only grains with planes oriented parallel to the substrate could be observed by a $\theta-2 \theta$ scan. The calculated grain size of $\mathrm{H}_{2^{-}}$ CVD W, at-H-CVD W and HWALD W ranged from 8.3 to $14.1 \mathrm{~nm}, 7.0$ to $21.6 \mathrm{~nm}$, and 5.2 to $10.3 \mathrm{~nm}$, respectively. Hence, HWALD possessed the smallest value and narrowest range of grain size. A smaller grain size suggests a larger number of grain boundaries in the film. This can contribute to a higher electrical resistivity of the HWALD $\beta$-W compared to the CVD $\alpha-\mathrm{W}$.

Impurities, especially oxygen, can enhance the formation and stability of $\beta-\mathrm{W} .^{46-50}$ For example, $\beta$-W is mostly formed during hydrogen reduction of tungsten oxides. ${ }^{51-53}$ In addition, a transition from the $\beta$ to the $\alpha$ phase can be achieved by annealing above $700{ }^{\circ} \mathrm{C}$ due to the removal of incorporated oxygen and enhancing the mobility of $\mathrm{W}$ atoms. ${ }^{38,39}$ On the other hand, in practice, oxygen is commonly present in PVD and CVD chambers, in residual (mainly water vapor) gases. Our experiments were conducted at a background pressure of $10^{-7} \mathrm{mbar}$, giving the impinging flux of background residuals of about 0.1 monolayer/s. ${ }^{54}$ The deposition rate of HWALD W was approximately 0.02 monolayer/cycle with a total purge time of $50 \mathrm{~s}$ per cycle. This results in the arrival flux of background residuals to the substrate of 5 monolayer/cycle.

Considering the low growth rate $(0.006 \mathrm{~nm} / \mathrm{cycle}$ for HWALD compared to $1.43 \mathrm{~nm} / \mathrm{min}$ for $\mathrm{H}_{2}$-CVD and $0.104 \mathrm{~nm} / \mathrm{min}$ for at-H-CVD) and long purge time, the films are therefore expected to be contaminated by oxygen. Namely, when the film is exposed to at- $\mathrm{H}$ after a $\mathrm{WF}_{6}$ pulse, fluorine adsorbed on the surface can (partially) be removed, leaving a reactive surface of tungsten, possibly with dangling bonds. During the following purge pulse, the background residuals such as water will arrive at the surface in quantities sufficient to fully oxidize it. The film (presumably up to several monolayers below the surface) can further be reduced back to tungsten by the upcoming at-H pulses. This growth mechanism via intermediate oxidation should result, based on the literature, in $\beta$-tungsten instead of $\alpha$-tungsten. To note, compositional analysis of the HWALD $\beta$-W by XPS (Fig. 6) reveals a high-purity tungsten, with the share of W approaching 99 at. \%. This implies that oxygen is efficiently removed during exposures to at- $\mathrm{H}$, i.e., by reduction reaction.

Cross-sectional HRTEM images of HWALD W with a-Si capping layer are presented in Fig. 9. In Fig. 9(a), a rough film can be observed with a film thickness varying between 10 and $18 \mathrm{~nm}$. This height variation is in agreement with the AFM results in Fig. 5(c). Figure 9(b) shows the same film at a higher magnification and exposes individual crystal grains. The visual grain size in Fig. 9(b) is on the order of $10 \mathrm{~nm}$; the film roughness is probably determined by different grain sizes and
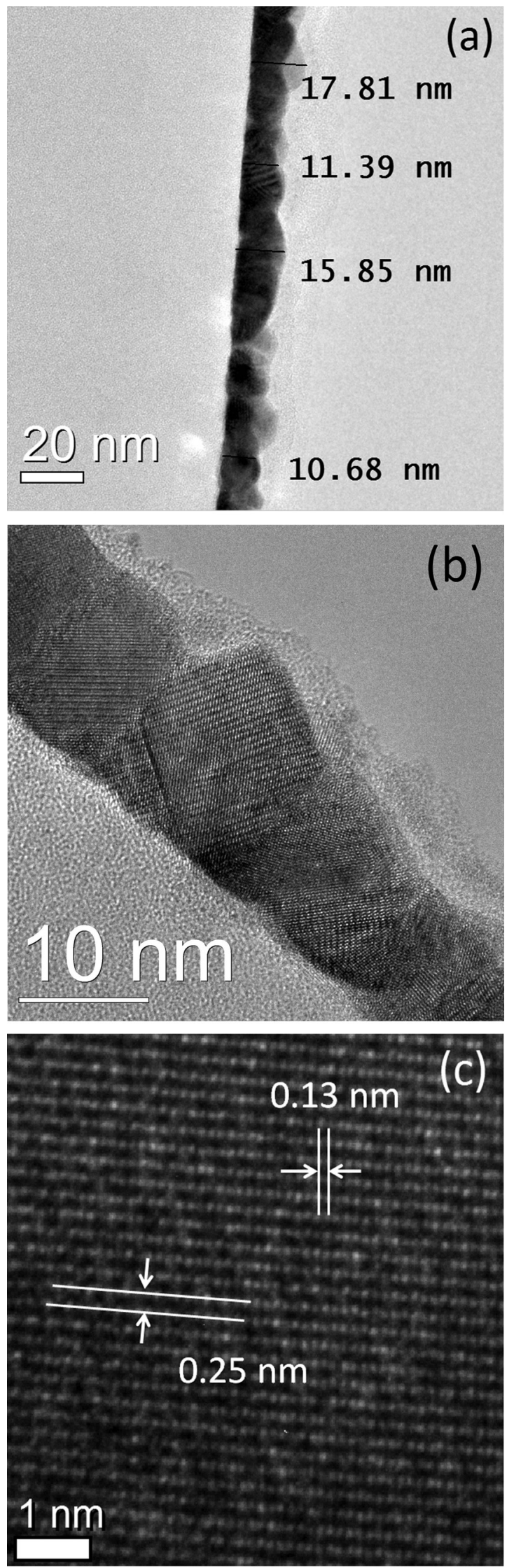

FIG. 9. Representative HRTEM cross-sectional images of a HWALD W film with a 5-nm a-Si capping layer. Individual crystal grains can be clearly seen in (a) and (b). The close-up of one grain and $d$-spacing, as calculated by FFT, are displayed in (c). 

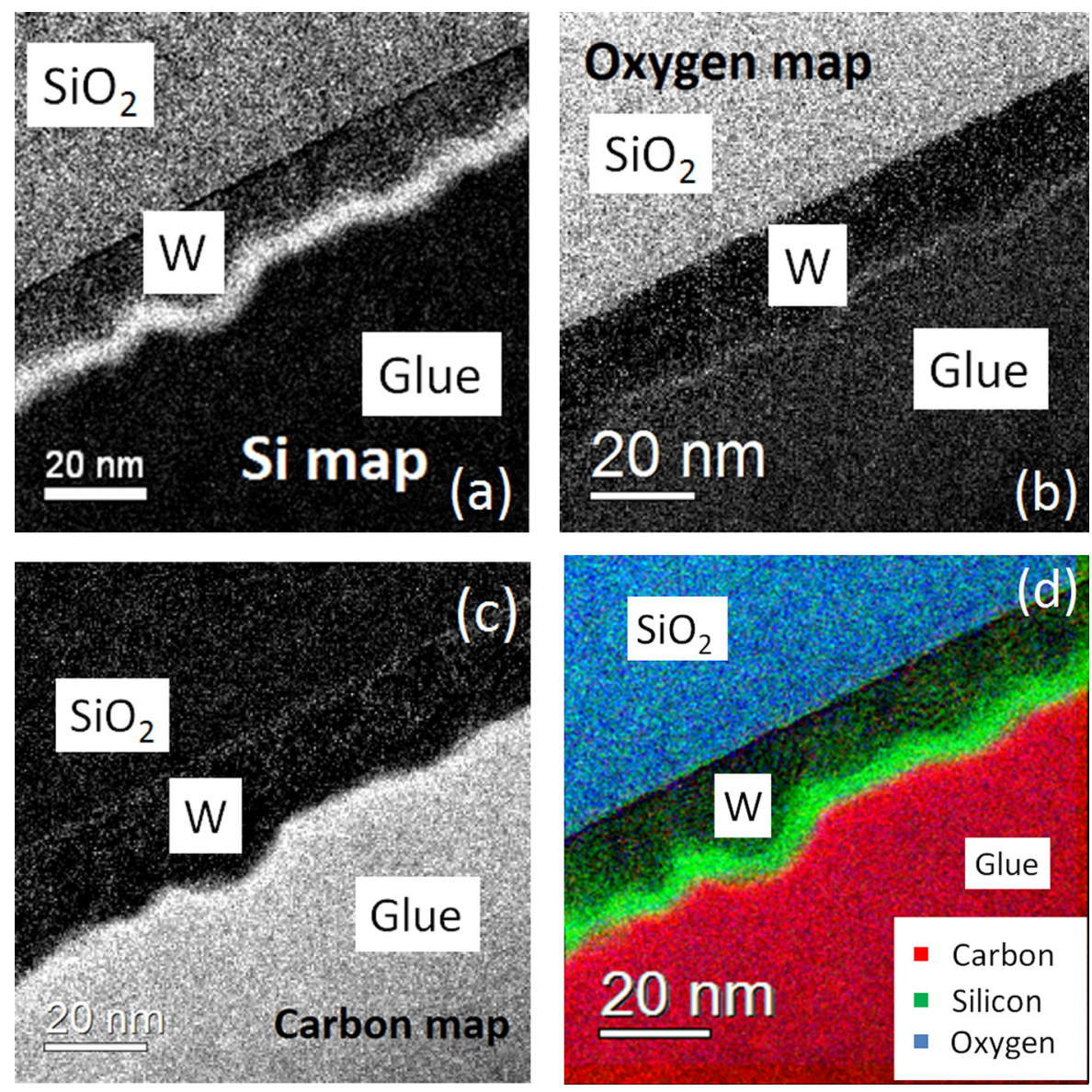

FIG. 10. (Color online) EFTEM images of a HWALD W film with a-Si capping layer: (a)-(c) present element mapping on gray scale (brighter regions denote higher concentrations); (d) is the elemental mapping combining carbon, silicon, and oxygen.

orientations. Figure 9(c) shows a close-up view of one grain. The $d$-spacing values calculated by fast Fourier transform (FFT) are $0.1361 \pm 0.0005$ and $0.2553 \pm 0.0012 \mathrm{~nm}$, respectively. This corresponds to (123) and (012) planes of $\beta$-W, which confirms the XRD results of Fig. 8.

No obvious interfacial layer between the $\mathrm{W}$ seed layer and the HWALD W layer is visible; the grains continue from the $\mathrm{SiO}_{2}$ layer to top surface. This phenomenon indicates that the seed layer is likely to have the same crystal structure and is $\beta-\mathrm{W}$ as well. It has been reported that tungsten layer can absorb oxygen from surrounding $\mathrm{SiO}_{2}$ during W CVD at a substrate temperature of $300{ }^{\circ} \mathrm{C}^{55}$ On the other hand, a $\mathrm{W}$ seed layer was proven to react with $\mathrm{O}$ at the $\mathrm{W}-\mathrm{SiO}_{2}$ interface in our case, shown in Fig. 7, implying that the $\mathrm{W}$ seed layer in our case can, in principle, incorporate oxygen from the $\mathrm{SiO}_{2}$ beneath, thereby forming the metastable $\beta$ phase.

EFTEM was employed to provide mapping of carbon, silicon, and oxygen in the HWALD W sample with a-Si capping layer. Fig. 10 shows the concentrations of mapped elements. The 5-nm thin capping layer can be clearly seen in Fig. 10(a). The visual appearance of Si inside the W layer is due to comparable energy loss peaks of $\mathrm{Si}$ and $\mathrm{W}$. Oxygen is absent in the W layer and is only visible in the $\mathrm{SiO}_{2}$ substrate and the oxidized capping layer, which is consistent with
XPS results (Fig. 6). The Red-green-blue image in Fig. 10(d) combines all the elements. Together with the XPS results (Fig. 6), this confirms the high purity of the $\mathrm{W}$ layer.

\section{SUMMARY AND CONCLUSIONS}

In this work, we characterized and compared tungsten (W) layers deposited by three different methods: (1) thermal CVD with molecular hydrogen and $\mathrm{WF}_{6}$ gas, (2) thermal CVD by atomic hydrogen and $\mathrm{WF}_{6}$, and (3) hot-wire assisted thermal ALD using atomic hydrogen and $\mathrm{WF}_{6}$. Before the deposition, a 3-nm W layer was formed as a seed layer. An in situ spectroscopic ellipsometer was adopted to monitor the thickness of grown films. Among the three methods, W obtained by HWALD possessed the highest resistivity of $100 \mu \Omega \cdot \mathrm{cm}$ and the lowest density of $17.15 \mathrm{~g} / \mathrm{cm}^{3}$, related to its appearance in the crystalline $\beta$-phase. In contrast, both CVD methods resulted in $\alpha$-phase $\mathrm{W}$ with a resistivity around $20 \mu \Omega \cdot \mathrm{cm}$ and a density of roughly $19 \mathrm{~g} / \mathrm{cm}^{3}$. XPS revealed a reaction between $\mathrm{W}$ and $\mathrm{SiO}_{2}$ at the interface of the seed layer and the substrate. Besides, no obvious interfacial layer could be seen between HWALD W and the seed layer of W. Remarkably, the grown HWALD $\beta$-W films possessed the lowest resistivity values in the range known for $\beta$ W up to date. 


\section{ACKNOWLEDGMENT}

The authors thank the Dutch Technology Foundation (STW) for the financial support of this project (STW12846).

${ }^{1}$ T. T. Kodas and M. J. Hampden-Smith, The Chemistry of Metal CVD (Wiley, Weinheim, 1994).

${ }^{2}$ J. D. Plummer, M. D. Deal, and P. B. Griffin, Silicon VLSI Technology: Fundamentals, Practice, and Modeling (Prentice Hall, Upper Saddle River, NJ, 2000).

${ }^{3}$ W. Kern and J. L. Vossen, Thin Film Processes II (Academic, San Diego, CA, 2012).

${ }^{4}$ H. Kim, J. Vac. Sci. Technol. B 21, 2231 (2003).

${ }^{5}$ M. Leskelä and M. Ritala, Thin Solid Films 409, 138 (2002).

${ }^{6}$ S. M. George, Chem. Rev. 110, 111 (2010).

${ }^{7}$ D. Longrie, K. Devloo-Casier, D. Deduytsche, S. V. D. Berghe, K. Driesen, and C. Detavernier, J. Solid State Sci. Technol. 1, Q123 (2012).

${ }^{8}$ O.-K. Kwon, S.-H. Kwon, H.-S. Park, and S.-W. Kang, J. Electrochem. Soc. 151, C753 (2004).

${ }^{9}$ O.-K. Kwon, S.-H. Kwon, H.-S. Park, and S.-W. Kang, Electrochem. Solid State Lett. 7, C46 (2004).

${ }^{10}$ H. Kim, Electrochem. Solid State Lett. 9, G323 (2006).

${ }^{11}$ Y. J. Lee and S. W. Kang, Electrochem. Solid State Lett. 5, C91 (2002).

${ }^{12}$ J. Mao, E. Eisenbraun, V. Omarjee, A. Korolev, C. Lansalot, and C. Dussarrat, ECS Trans. 33, 125 (2010).

${ }^{13}$ V. V. Afanas'ev, J. M. M. De Nijs, and P. Balk, J. Appl. Phys. 78, 6481 (1995).

${ }^{14}$ A. H. Mahan, A. C. Dillon, L. M. Gedvilas, D. L. Williamson, and J. D. Perkins, J. Appl. Phys. 94, 2360 (2003).

${ }^{15}$ A. H. Mahan, J. Carapella, B. P. Nelson, R. S. Crandall, and I. Balberg, J. Appl. Phys. 69, 6728 (1991).

${ }^{16}$ Y. Shi, Acc. Chem. Res. 48, 163 (2015).

${ }^{17}$ H. Shimizu, K. Sakoda, T. Momose, and Y. Shimogaki, Jpn. J. Appl. Phys. 51, 05EB02 (2012).

${ }^{18}$ B. Stannowski, J. K. Rath, and R. E. Schropp, Thin Solid Films 395, 339 (2001).

${ }^{19}$ I. Langmuir, J. Am. Chem. Soc. 34, 860 (1912).

${ }^{20}$ I. Langmuir and G. M. J. Mackay, J. Am. Chem. Soc. 36, 1708 (1914).

${ }^{21}$ I. Langmuir, J. Am. Chem. Soc. 37, 417 (1915).

${ }^{22}$ H. Matsumura and H. Tachibana, Appl. Phys. Lett. 47, 833 (1985).

${ }^{23}$ E. Lassner and W. D. Schubert, Tungsten: Properties, Chemistry, Technology of the Elements, Alloys, and Chemical Compounds (Springer Science \& Business Media, New York, 1999).

${ }^{24}$ K. Nakagawa, M. Fukuda, S. Miyazaki, and M. Hirose, MRS Proc. 452, 243 (1996).

${ }^{25}$ J. E. J. Schmitz, Chemical Vapor Deposition of Tungsten and Tungsten Silicides for VLSI/ULSI Applications (Noyes, Park Ridge, NJ, 1992), p.12.
${ }^{26}$ M. Yang, A. A. Aarnink, A. Y. Kovalgin, R. A. Wolters, and J. Schmitz, Phys. Status Solidi A 212, 1607 (2015).

${ }^{27}$ H. Van Bui, A. Y. Kovalgin, and R. A. M. Wolters, J. Solid State Sci. Technol. 1, P285 (2012).

${ }^{28}$ H. Van Bui, A. Y. Kovalgin, A. A. I. Aarnink, and R. A. M. Wolters, J. Solid State Sci. Technol. 2, 149 (2013).

${ }^{29}$ A. Y. Kovalgin and A. A. I. Aarnink, U.S. patent 20130337653 A1 (14 June 2013).

${ }^{30}$ D. A. Outka, Surf. Sci. 235, L311 (1990).

${ }^{31}$ R. Warncke, M. L. Gerwien, and L. Gmelin, Gmelin Handbook of Inorganic Chemistry, Tungsten, Suppl. No. 54, 8th ed. (Springer, Heidelberg, 1989).

${ }^{32} \mathrm{~S}$. Bystrova, "Diffusion barriers for Cu metallisation in $\mathrm{Si}$ integrated circuits: deposition and related thin film properties," Ph.D. thesis (University of Twente, 2004).

${ }^{33}$ F. Allen, O. Kennard, D. Watson, L. Brammer, A. Orpen, and R. Taylor, International Tables for Crystallography (Kluwer Academic, Dordrecht, 1995), Vol. C.

${ }^{34}$ W. Morcom, W. Worrell, H. Sell, and H. Kaplan, Metall. Trans. 5, 155 (1974).

${ }^{35}$ T. Millner, A. J. Hegedüs, K. Sasvári, and J. Neugebauer, Z. Anorg. Allg. Chem. 289, 288 (1957).

${ }^{36}$ P. Petroff, T. Sheng, A. Sinha, G. Rozgonyi, and F. Alexander, J. Appl. Phys. 44, 2545 (1973).

${ }^{37}$ S. Basavaiah and S. Pollack, J. Appl. Phys. 39, 5548 (1968).

${ }^{38}$ Y. Shen and Y. Mai, Mater. Sci. Eng. A 284, 176 (2000).

${ }^{39}$ C. Tang and D. Hess, Appl. Phys. Lett. 45, 633 (1984).

${ }^{40}$ A. Lita, D. Rosenberg, S. Nam, A. Miller, D. Balzar, L. Kaatz, and R. Schwall, IEEE Trans. Appl. Supercond. 15, 3528 (2005).

${ }^{41}$ A. Bartl, "Fundamentals of NS-tungsten powder manufacture," Ph.D. thesis (TU Vienna, 1997.)

${ }^{42}$ Q. Hao, W. Chen, and G. Xiao, Appl. Phys. Lett. 106, 182403 (2015).

${ }^{43}$ P. Petroff and W. Reed, Thin Solid Films 21, 73 (1974).

${ }^{44}$ J. R. Rairden, U.S. patent 3504325 A (31 March 1970).

${ }^{45}$ A. Patterson, Phys. Rev. 56, 978 (1939).

${ }^{46}$ D. P. Basile, C. L. Bauer, S. Mahajan, A. G. Milnes, T. N. Jackson, and J. Degelormo, Mater. Sci. Eng. B 10, 171 (1991).

${ }^{47}$ A. Bensaoula, J. C. Wolfe, A. Ignatiev, F. O. Fong, and T. S. Leung, J. Vac. Sci. Technol. A 2, 389 (1984).

${ }^{48}$ M. J. O'keefe and J. T. Grant, J. Appl. Phys. 79, 9134 (1996).

${ }^{49}$ Y. Pauleau, P. Lami, A. Tissier, R. Pantel, and J. C. Oberlin, Thin Solid Films 143, 259 (1986).

${ }^{50}$ J. H. Souk, J. F. O'hanlon, and J. Angillelo, J. Vac. Sci. Technol. A 3, 2289 (1985).

${ }^{51}$ M. Charlton, Nature 169, 109 (1952).

${ }^{52}$ M. Charlton, Nature 174, 703 (1954).

${ }^{53}$ G. Mannella and J. O. Hougen, J. Phys. Chem. 60, 1148 (1956).

${ }^{54}$ J. Orloff, Handbook of Charged Particle Optics (CRC, Boca Raton, FL, 2008).

${ }^{55}$ D. C. Paine, J. C. Bravman, and C. Yang, Appl. Phys. Lett. 50, 498 (1987). 